\title{
DIAGNÓSTICO PRELIMINAR DAS ENXURRADAS NO ALTO CURSO DA BACIA HIDROGRÁFICA DO RIO SANTO ANTÔNIO, SÃO LUÍS- MA
}

\author{
Jacilene Marques Camara ${ }^{(a)}$, Quésia Duarte da Silva ${ }^{(b)}$, Danyella Vale Barros França ${ }^{(c)}$, Ricardo \\ Gonçalves Santana ${ }^{(d)}$
}

(a) Graduanda em Geografia Bacharelado/Departamento de História e Geografia/Universidade Estadual do Maranhão jacy_llene@ hotmail.com

(b) Professora do Departamento de História e Geografia/Universidade Estadual do Maranhão, quesiaduartesilva@hotmail.com

(c) Graduada em Geografia Licenciatura e Bacharelado/BolsistaTécnica Nível II/Universidade Estadual do Maranhão danyellabarros-geo@hotmail.com

(d) Graduando em Geografia Bacharelado/Departamento de História e Geografia/Universidade Estadual do Maranhão ricardogsantana19@hotmaill.com

\section{Eixo: GEOGRAFIA FÍSICA E DESASTRES NATURAIS}

\begin{abstract}
Resumo
As enxurradas são desastres correlacionados ao escoamento superficial de elevada agilidade e energia, provocado por chuvas intensas, mas também estão relacionados aos processos de impermeabilização do solo, durante o processo de urbanização. Partindo deste pressuposto, objetivou-se neste trabalho apresentar de maneira preliminar a ocorrência de enxurradas no alto curso da bacia hidrográfica do Santo Antonio. Para o alcance destes objetivos realizou-se um levantamento bibliográfico e trabalhos de campo para a checagem preliminar das áreas com ocorrência de enxurradas na área em questão. Quatro bairros foram diagnosticados com os fenômenos supracitados, sendo eles Jardim Tropical I e II, Santa Efigênia, Cidade Olímpica e Mata. Conclui-se que existem áreas com ocorrência de enxurradas no alto curso da bacia em questão e que diversas pessoas têm sido afetadas. Acredita-se que este e outros trabalhos poderão ser utilizados para minimizar estes problemas na área urbana da Ilha do Maranhão.
\end{abstract}

Palavras chave: Enxurradas; Alto curso da bacia hidrográfica do Santo Antonio; Ilha do Maranhão.

\section{Introdução}

As paisagens têm sido alteradas de forma acelerada nos últimos anos, devido ao crescente processo de urbanização e a necessidade de locais para o exercício das atividades humanas. Segundo Jorge (2011), a preocupação com a influência do ser humano na natureza iniciou-se no Brasil em meados de 1950 com a obra Sítio Urbano de São Paulo do renomado Ab'Sáber. No entanto, mesmo com esta preocupação despertada há anos, somente nas últimas décadas percebeu-se uma demanda maior de pesquisas e estudos relacionados a essas questões. Nos últimos 60 anos, as cidades brasileiras vêm passando por um crescente processo de urbanização, o qual tem se caracterizado pelo uso inadequado do solo e a ocupação desordenada dos espaços. Com essas características, o referido processo tem como consequências diretas 
as rápidas modificações no solo e nos sistemas fluviais, as quais, na maioria dos casos, tem sido irreversíveis para o ambiente.

Partindo disto, entende-se que o processo de urbanização tem provocado inúmeros problemas ambientais e sociais ao longo dos anos, principalmente porque em sua maioria, o processo de urbanização se dá de forma não planejada. Inseridos neste processo, indivíduos com baixo poder aquisitivo tendem a ocupar espaços urbanos bastantes desvalorizados e frágeis do ponto de vista ambiental, como os leitos dos canais fluviais, encostas, planícies de maré e ambientes suscetíveis a quaisquer desastres naturais.

De acordo com Tominaga (2011), desastres naturais são fenômenos naturais ou provocados pela sociedade humana sobre um ecossistema, podendo causar danos humanos, materiais e consequentemente prejuízos econômicos e sociais. Em São Luís do Maranhão, observa-se que as bacias hidrográficas estão sendo modificadas pela artificialização (inserção de casas, pontes, estradas, etc.) do cenário natural, alterando-o, por sua vez, tanto quantitativamente, quanto qualitativamente.

As enxurradas são provocadas por chuvas intensas e concentradas em curto período, em regiões de relevo acidentado, caracterizando-se pela elevação súbita e violenta dos caudais, que, em seguida, escoam de forma rápida e intensa (CASTRO et al., 2007). De acordo com o Anuário Brasileiro de Desastre Naturais (2012), enxurradas são desastres correlacionados ao escoamento superficial de elevada agilidade e energia, provocados por chuvas intensas e centralizadas, bastante frequentes em relevos acidentados, ocorrendo, em geral, em bacias hidrográficas de pequenas dimensões, "pois o fenômeno geralmente é circunscrito a uma pequena área" (SAUSEN \& NARVAES, 2015, p. 121). Já para Amaral e Ribeiro (2009) a enxurrada é o escoamento superficial concentrado e com alta energia de transporte, que pode ou não estar associado a áreas de domínio dos processos fluviais.

Apesar da discussão conceitual, sabe-se que este é um fenômeno de ocorrência natural no ambiente, e que este pode ser agravado em localidades que estejam suscetíveis aos processos de impermeabilização do solo, causados pela urbanização desordenada. Essa impermeabilização contribui na diminuição da capacidade de infiltração das águas pluviais resultando no aumento das cheias. Neste sentido, objetivou-se neste trabalho diagnosticar de maneira preliminar a ocorrência de enxurradas no alto curso da bacia hidrográfica do Santo Antonio através de trabalhos de campo e mapeamento diagnóstico.

\section{Materiais e Métodos}

Para alcançar o objetivo proposto, adotou-se os procedimentos técnico-operacionais da pesquisa quantitativa alicerçados em Minayo (2000), através da revisão de literatura especializada no que tange a 


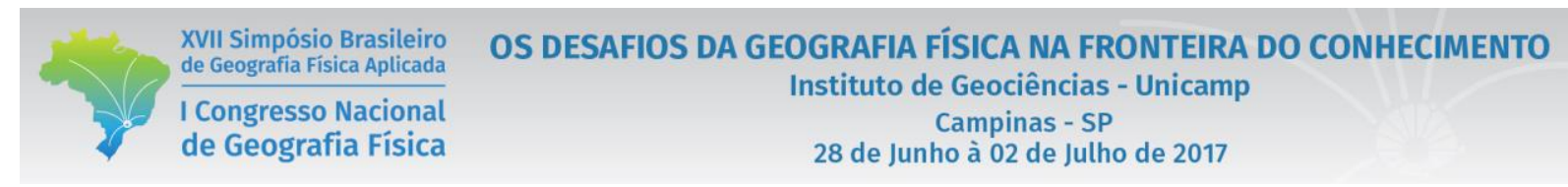

desastres, enchentes, inundações, enxurradas, alagamentos, geomorfologia urbana e dentre outros. Foram realizados três trabalhos de campo afim de diagnosticar as áreas com ocorrência de enxurradas. Conversou-se com a população local, onde a mesma relatou as dificuldades enfrentadas em relação às enxurradas que acontecem anualmente. Com as informações de campo e dos populares, elaborou-se o mapa de localização da área de estudo e em laboratório foi feita a plotagem preliminar das áreas de enxurradas no programa ArcGis da ESRI, versão 10.2.

\section{$3 \quad$ Resultados e Discussões}

A área objeto de estudo está localizada na porção nordeste da Ilha do Maranhão, compreendendo o município de São Luís e parte de São José de Ribamar. Limita-se ao norte com a bacia hidrográfica do Paciência, ao sul com a bacia do rio Jeniparana, a leste com o médio Santo Antonio e a oeste com a bacia do Bacanga (Figura 1).

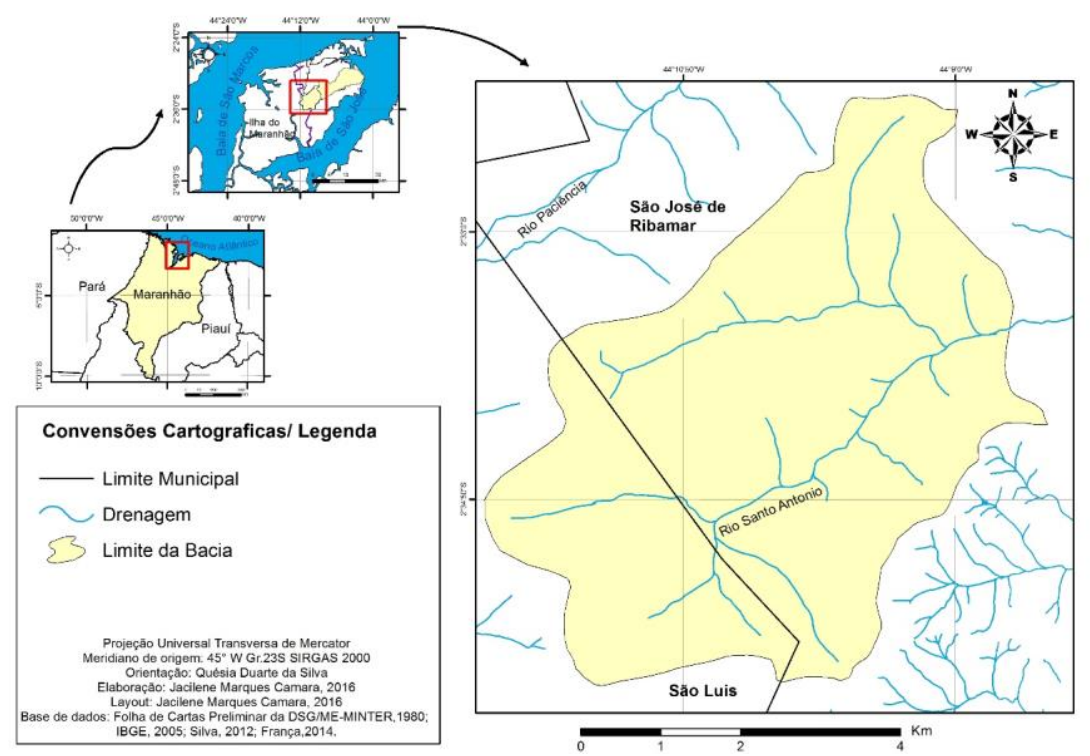

Figura1 - Mapa de localização do alto curso da bacia hidrográfica do Rio Santo Antonio

Por estar a nordeste da Ilha do Maranhão, em termos geológicos, a área de estudo localiza-se a nordeste da bacia costeira de São Luís e apresenta afloramentos do Grupo Barreiras e Formação Açuí (CARVALHO, 2007). As unidades de relevo presentes na área de estudo são os tabuleiros com topos planos e as planícies fluviais. Associadas a essas morfologias, segundo Carvalho (2007) tem-se os Neossolos quartizarênicos órticos nos tabuleiros e os Gleissolos nas planícies fluviais. Em termos de declividade, preliminarmente, pode-se afirmar que elas variam em torno de 0 e $6 \%$ com altitudes entre 45 e 20 metros (no alto curso). No que tange ao uso e cobertura do solo, a área encontra-se totalmente urbanizada, porém ainda existe mata 


\section{OS DESAFIOS DA GEOGRAFIA FÍSICA NA FRONTEIRA DO CONHECIMENTO \\ Instituto de Geociências - Unicamp \\ Campinas - SP \\ 28 de Junho à 02 de Julho de 2017}

ciliar no canal principal do rio em questão. Já nos canais tributários as planícies fluviais, áreas que deveram estar protegidas pela mata ciliar, encontram-se totalmente ocupadas por estabelecimentos residências e comerciais.

Segundo Ferreira (2003), na área do alto curso da bacia do rio Santo Antônio, as atividades antrópicas foram intensificadas ao longo das duas últimas décadas, acarretando sérias consequências ambientais, devido à construção de obras de engenharia com níveis diferenciados de interferência no espaço. O leito do rio vem passando por vários problemas ambientais, devido ao lançamento de efluentes domésticos provocando assoreamento, contaminação e poluição das águas, e comprometendo o uso doméstico da água. Muitas casas foram construídas no leito menor do canal fluvial, o que tem causado os fenômenos de inundação com danos materiais, porém muitas famílias têm enfrentado sérios problemas com os eventos de enxurradas na referida área de estudo e ao longo dos anos pessoas tem perdido bens materiais de maneira significativa na localidade estudada.

A área estudada encontra-se bem urbanizada, com edificações bem consolidadas, solo extremamente impermeabilizado e sem infraestrura no que diz respeito ao saneamento básico e sistema de drenagem urbana das águas pluviais. Em conversa com moradores, constatou-se que nos últimos nove anos e durante o período chuvoso, dezenas de pessoas têm suas casas tomadas pela enxurrada (Figura 2). As ruas e avenidas ficam intrafegáveis na maioria dos bairros inseridos no alto curso da bacia hidrográfica do Santo Antonio devido à quantidade e a velocidade do escoamento superficial. Não são necessários grandes volumes pluviométricos para que a enxurrada tome grandes proporções nas ruas e avenidas (Figura 3) e todo o ambiente e relações sociais ficam comprometidas depois de alguns poucos minutos/horas de chuvas. Até o momento diagnosticou-se de maneira preliminar a ocorrência de enxurradas nos bairros Jardim Topical I e II, Cidade Olímpica, Santa Efigênia e Mata.

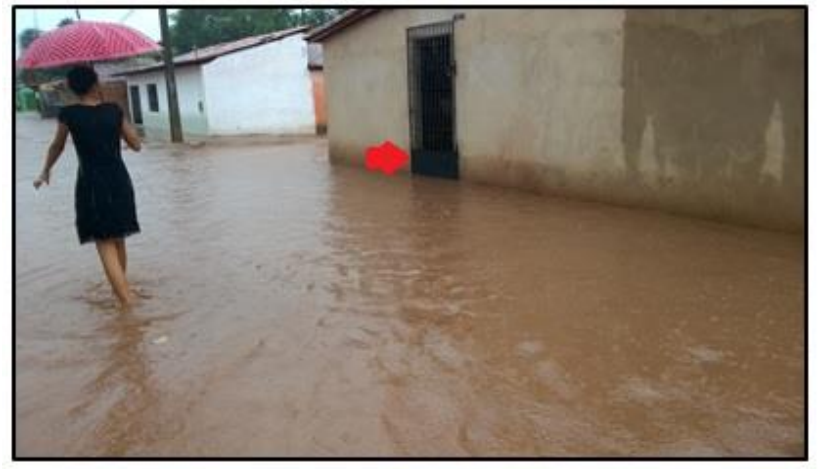

Figura 2 - Área alagada por enxurrada no bairro Jardim Tropical I. A seta vermelha indica a contenção feita por moradores para impedir a passagem da água para a residência em março de 2015. 

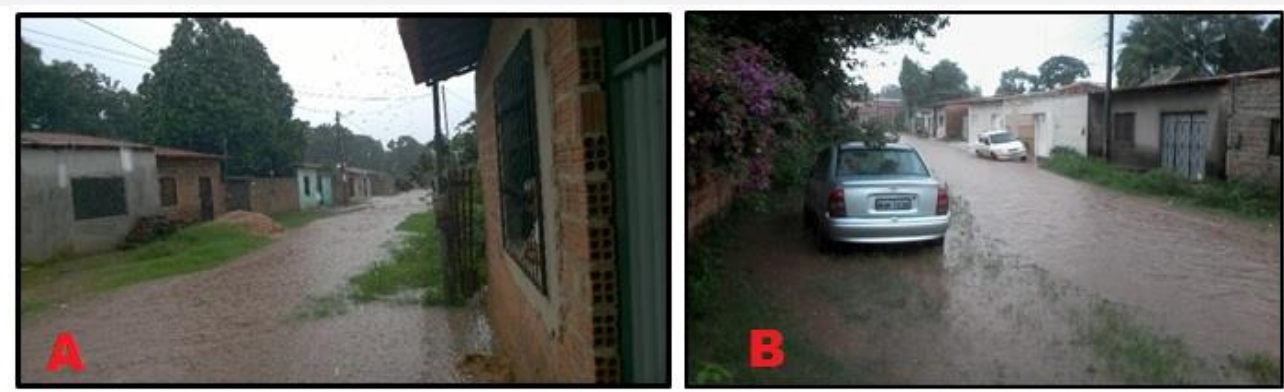

Figura 3A e 3B - Fenômeno de enxurrada no bairro Jardim Tropical I, no alto curso da bacia hidrográfica do Santo Antonio

\section{Conclusão}

Nos últimos anos, o estudo das bacias hidrográficas urbanas inseridas na Ilha do Maranhão tem sido bem intensificado, principamente no que tange aos processos ambientais urbanos como enchentes, inundações, alagamentos, enxurradas, movimentos de massa e dentre outros. De maneira preliminar e na área objeto de estudo, já foram identificados cinco bairros com a ocorrência de enxurradas, porém infere-se que existam mais bairros com a mesma problemática na área de estudo. Acredita-se que estes estudos devem continuar, pois são de suma importancia para o melhor gerenciamento dos espaços e das condições de vida humana existentes hoje na Ilha do Maranhão. Quanto à ocupação dos solos, neste trabalho, pode-se constatar até o momento, que o uso inadequado do solo associado à falta de planejamento urbano tem sido o fator deflagrador dos problemas de enxurradas no alto curso da bacia hidrográfica do Santo Antonio.

\section{Referências}

AMARAL, R.; RIBEIRO, R. R. Inundações e Enchentes. In: Desastres Naturais: Conhecer para Prevenir. TOMINAGA, L. K.; SANTORO, J.; AMARAL, R. (Orgs.) Instituto Geológico, Secretaria do Meio Ambiente, Governo do Estado de São Paulo. 2012.

BRASIL. Anuário brasileiro de desastres naturais: 2011. Ministério da Integração Nacional. Secretaria Nacional de Defesa Civil. Centro Nacional de Gerenciamento de Risco e Desastre. Centro Nacional de Gerenciamento de Riscos e Desastres. Brasília: CENAD, 2012.

CASTRO, A. L. C. CALHEIROS, L. B. CUNHA, M. I. R. BRINGEL, M. L. N. C. Manual de desastres: desastres naturais. Brasília, 2007. p. 182.

CARVAlHO, A. M. A. de. Usos e Impactos Ambientais no Estuário e Entorno do Rio Santo Antonio em Paço do Lumiar - MA: uma abordagem geossistêmica. Monografia de Graduação - Curso de Geografia, Universidade Estadual do Maranhão, 2007. p. 82. 
FERREIRA, Maria de Jesus. Impactos ambientais recentes na área da bacia do rio Santo Antônio, Paço do Lumiar Ma. 2003. 41f. Monografia. (Graduação em Geografia) - Universidade Federal do Maranhão, São Luís.

JORGE, M. C.O Geomorfologia Urbana: conceitos, métodos e teorias. In: GUERRA, A. T. (org). Geomorfologia Urbana. Rio de Janeiro: Bertrand Brasil. p. 117 - 145, 2011.

MARCONI, M. A. LAKATOS, M. E. Técnicas de pesquisa: planejamento e execução de pesquisas, amostragens e técnicas de pesquisas, elaboração análise e interpretação de dados. 4 ed. São Paulo: Atlas, 1999.

MINAYO, M. C. S. Pesquisa social: teoria método e criatividade. 16 ed. Petrópolis: Vozes, 2000.

SAUSEN, T. M. NARVAES, I. S. Sensoriamento remoto para inundação e enxurrada. In: Sensoriamento Remoto para Desastres. SAUSEN, T. M.; LACRUZ, M. S. P. (Orgs) São Paulo: Oficina de textos. 2015. p. 119-142.

TOMINAGA, L. K. Desastres Naturais: Por que ocorrem? In: Desastres Naturais: Conhecer para Prevenir.

TOMINAGA, L. K.; SANTORO, J.; AMARAL, R. (Org) Instituto Geológico, Secretaria do Meio Ambiente, Governo do Estado de São Paulo. 2012. 